\title{
Arcabouço estrutural da Mina Bananeira, Miguel Calmon, Bahia: uma contribuição ao estudo da evolução tectônica do Orógeno Itabuna-Salvador-Curaçá
}

\author{
Simone Cerqueira Pereira Cruz ${ }^{1 *}$, Carlson de Matos Maia Leite ${ }^{1}$, \\ Marcelo Antônio Gonçalves Conceição ${ }^{2}$
}

\begin{abstract}
Resumo O Orógeno Salvador-Curaçá posiciona-se na porção nordeste do Cráton do São Francisco e representa uma incisão orogênica paleoproterozoica gerada a partir da colisão entre os blocos Gavião, Serrinha, Jequié e Itabuna-SalvadorCuraçá. Este trabalho apresenta os resultados da análise estrutural realizada na Mina Bananeira, no Município de Miguel Calmon (BA), onde aflora uma sequência supracrustal, de idade ainda controversa, rica em manganês. Duas famílias de estruturas foram identificadas, uma compressional, constituída pelas estruturas das fases Dn-1, Dn, Dn+1 e Dn+2, que corresponde às fases tangencial e transpressional sinistral, respectivamente. Nesse contexto, pode ser encontrada uma foliação Sn-1//Sn que foi dobrada (Fase Dn+1). Zonas de cisalhamento foram nucleadas na fase final de deformação compressional (Fase Dn+2). O acervo mais jovem é marcado pela presença de zonas de cisalhamento normais, rúptildúcteis (Fase Dn+3) e de estruturas rúpteis caracterizadas por zonas de cisalhamento cataclásticas e fraturas de extensão, nas quais há remobilização de manganês.
\end{abstract}

Palavras-chave: zonas de cisalhamento; foliação; transpressão.

Abstract Structural framework of Bananeira Mine, Miguel Calmon, Bahia: a contribution to study of the tectonic evolution of the Itabuna-Salvador-Curaçá Orogen. The Salvador-Curaçá Orogen is located in the northeastern portion of the São Francisco Craton. It represents a paleoproterozoic orogenic incision due to the collision among the Gavião, Serrinha, Jequié e Itabuna-Salvador-Curaçá blocks. This paper shows the main results of the structural analysis in the Bananeira Mine, Miguel Calmon District, Bahia, where outcrops a manganese-rich supracrustal sequence of uncertain age. Two structural families were identified: one compressional composed by Dn-1, Dn, Dn +1 and Dn +2 structures that correspond to the tangential and left-hand transpressional ductile deformation phases, respectively. In this context there is a Sn-1//Sn foliation that was folded by the Dn phase. Shear zones (Dn+2) were nucleated during the last stages of the compressional phase. The youngest structures are marked by brittle-ductile normal shear zones (Dn +3 phase) and brittle structures characterized by cataclastic shear zones and traction fractures with manganese concentrations.

Keywords: shear zone; foliation; transpression.

INTRODUÇÃO O Orógeno Itabuna-

Salvador-Curaçá (Fig. 1) representa uma incisão paleoproterozoica (ca. 2,0 - 2,2 Ga) que justapõe dois compartimentos geológicos distintos: o ocidental, representado pelo Bloco Gavião, com infraestrutura composta por rochas de idades arqueanas entre 3,4 e 2,7 Ga (Mougeot 1996, Peucat et al. 2002), e o oriental, representado pelos Blocos Serrinha, Jequié e ItabunaSalvador-Curaçá, com infraestruturas composta por rochas de idades arqueanas $(3,2-2,6 \mathrm{Ga})$ a paleoproterozoicas (2,2 - 2,0 Ga) (Silva et al. 1997, Bastos-Leal 1998, Barbosa \& Sabaté 2002, 2004, Pinho 2005). De acordo com Barbosa \& Sabaté (2002, 2004), as colisões entre esses blocos, durante o Paleoproterozoico (Riaciano/Orosiniano), teria levado à estruturação do orógeno, culminando com a formação de uma mega-flor positiva de expressão regional. Nessa megaestrutura, a porção ocidental está posicionada no limite entre os blocos Gavião, Jequié e Itabuna-Salvador-Curaçá, que é denominado de Lineamento Contendas-Jacobina (Sabaté et al. 1990a, Sabaté 1991) (Fig. 1). Esse lineamento representa a geossutura colisional que justapõe o compartimento ocidental e o oriental do orógeno (Fig. 1) e é constituído por um sistema de estruturas de empurrão e de transcorrência com direção aproximadamente meridional e vergência para oeste. Seu caráter de geossutura colisional é atestado por um alinhamento de granitos peraluminosos paleoproterozoicos com idades entre 2,15 e 1,88 Ga (Torquato et al. 1978, Cuney et al. 1990, Sabaté et al. 1990b, Marinho 1991, Leite 2002).

${ }^{1}$ Instituto de Geociências (IGEO) da Universidade Federal da Bahia - UFBA, Salvador (BA), Brasil. E-mails: simonecruzufba@gmail.com; carlson.leite@gmail.com

${ }^{2}$ MGC LTDA, Salvador (BA), Brasil. E-mail: mgcltda@ig.com.br

*Autor correspondente 
Mina Bananeira, situada a oeste do Lineamento Contendas-Jacobina (Fig. 1), guarda um espetacular acervo de estruturas tectônicas da evolução deformacional do evento orogênico paleoproterozoico no Estado da Bahia. Neste trabalho apresentamos e interpretamos a evolução estrutural desse acervo de modo a contribuir para melhor entendimento da evolução geotectônica do orógeno em foco.

Arcabouço geológico regional Aárea de estudo está posicionada no setor ocidental do Orógeno SalvadorCuraçá onde predominam as unidades do Bloco Gavião (Marinho \& Sabaté, 1982) (Fig. 1), cuja infraestrutura é composta por ortognaisses migmatizados (Melo et al. 1995) e pelo Greenstone Belt de Mundo Novo (Mascarenhas \& Silva, 1994), além de granitoides diversos. Associadas a essa infraestrutura ocorrem rochas metassedimentares que constituem o Grupo Jacobina (Leo et al. 1964) e o Complexo Saúde (Couto et al. 1978). Leucogranitos de idade riaciana-orosiriana (2,08-1,88 Ga, Torquato et al. 1978, Sabaté et al. 1990b, Leite 2002) são intrusivos nessas duas últimas unidades geotectônicas (Melo et al. 1995, Leite 2002, Leite et al. 2005, Leite et al. 2007).

Os ortognaisses migmatizados são de idades paleoarqueanas (3,4-3,2 Ga, Mougeot 1996, Peucat et al. 2002) e os granitoides associados neoarqueanos (2,8-2,7 Ga, Mougeot 1996, Peucat et al. 2002). Essas rochas estão metamorfisadas na fácies anfibolito (Melo et al. 1995).

O Greenstone Belt de Mundo Novo (Mascarenhas \& Silva 1994, Mascarenhas et al. 1998) é constituído por unidades metavulcânicas que variam de metabasaltos toleíticos a metandesitos e metadacitos calcialcalinos e por unidades metassedimentares, metamorfisadas nas fácies anfibolito/xisto verde (Mascarenhas \& Silva 1994 e Mascarenhas et al. 1998, Leite 2002). O vulcanismo félsico desse greenstone belt é datado em 3,3 Ga (Peucat et al. 2002). O empilhamento litoestratigráfico do Greenstone Belt de Mundo Novo é motivo de grande controvérsia, vez que as unidades metassedimentares pelíticas, incluídas nesse greenstone belt (Mascarenhas et al. 1998), eram antes definidas como integrantes ou do Grupo Jacobina (Leo et al. 1964), ou do Complexo Itapicuru (Couto et al. 1978), ou, ainda, do Complexo Saúde (Couto et al. 1978). Na falta de estudos complementares de estratigrafia e de análise de bacias, geologia estrutural e de petrologia, abordaremos essas unidades metassedimentares pelíticas na descrição do Grupo Jacobina e do Complexo Saúde, a seguir.

O Grupo Jacobina (Leo et al. 1964) representa uma bacia sedimentar assentada no antepaís do Lineamento Contendas-Jacobina (Fig. 1). O embasamento dessa bacia é constituído pelos ortognaisses-migmatíticos da infraestrutura do Bloco Gavião e das metavulcânicas do Greenstone Belt de Mundo Novo. Na área de estudo, no seu contato ocidental com o embasamento, ocorrem metaconglomerados e quartzitos subverticalizados, portadores de mineralizações auríferas. Essa associação de fácies constitui a Formação Serra do Córrego (Leo et al. 1964) e é interpretada como de origem fluvial (Leo et al. 1964, Griffon 1967, Molinari \& Scarpelli 1988) com leques aluviais associados (Mascarenhas et al. 1998). A Formação Serra do Córrego passa estruturalmente acima para a Formação Rio do Ouro (Leo et al. 1964), que é composta por quartzitos brancos ou esverdeados, associados a níveis delgados e descontínuos de metaconglomerados. Em domínios de menor deformação, os quartzitos exibem estratificação cruzada tangencial, ripples de onda e estratificações cruzadas do tipo espinha de peixe que sugerem protólitos depositados em ambiente litorâneo com ação de ondas e marés. Na parte

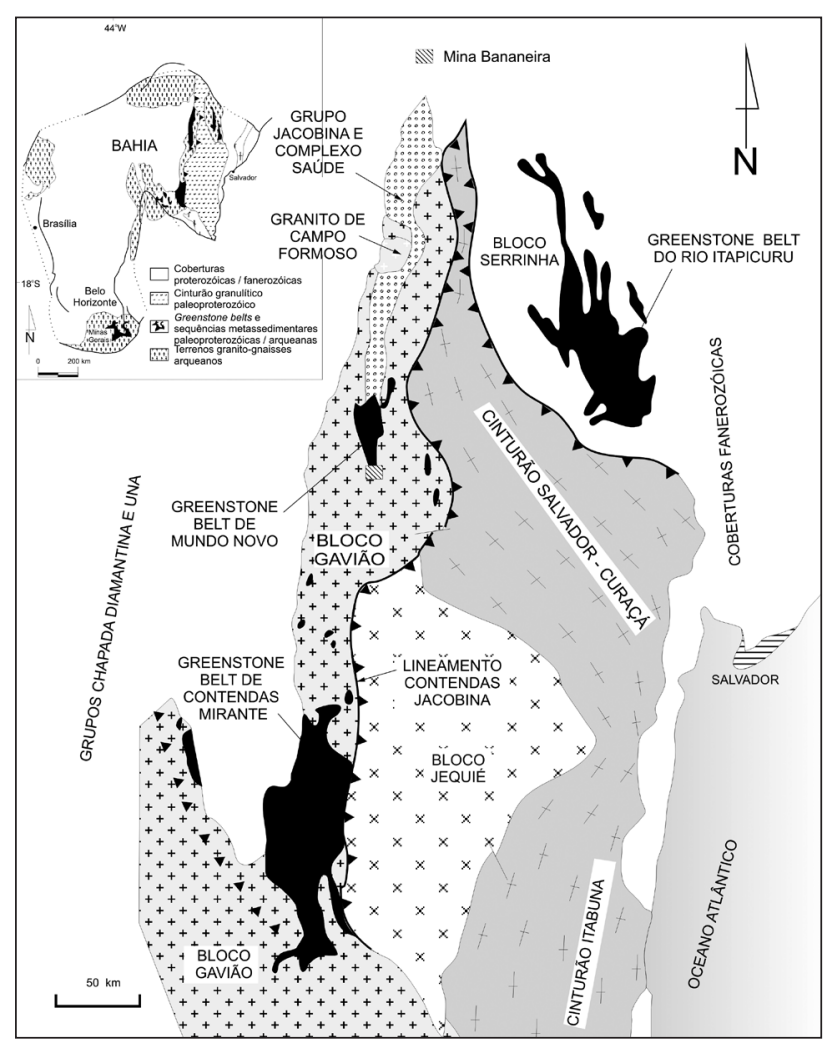

Figura 1 - Arcabouço tectônico regional com a localização da Mina Bananeira. Fonte: Leite (2002). 
sul do Grupo Jacobina, na região do povoado da Bananeira, os quartzitos da Formação Rio do Ouro estão sobrepostos, através de contatos cisalhados, por sillimanita-andaluzita xistos e filitos com níveis subordinados de metaconglomerados e de quartzitos. Os filitos mostram-se mineralizados em manganês e ferro. Essa associação de fácies dominantemente metapelítica apresenta variadas denominações, a saber: Formação Bananeiras (Leo et al. 1964), Grupo Jacobina Inferior (Griffon, 1967), Complexo Itapicuru (Couto et al. 1978) ou sequência metassedimentar do Greenstone Belt de Mundo Novo (Mascarenhas \& Silva 1994, Mascarenhas et al. 1998). No norte da área, essa sequência metassedimentar pelítica passa à outra associação de fácies mineralizada em manganês e barita e composta por xistos a clorita e sericita, filonitos, filitos, metacherts, quartzitos com níveis de andaluzita xistos e formações ferríferas bandadas. Essa sequência metassedimentar também tem recebido as mais diversas nomenclaturas litoestratigráficas, fruto de variadas interpretações sobre a origem da bacia e do Greenstone Belt de Mundo Novo: (i) Formação Cruz das Almas (Leo et al. 1964, Ledru et al. 1997); (ii) desmembrada por Griffon (1967), do topo para a base, em formações Cruz das Almas (xistos com níveis de quartzitos), Serra do Meio (quartzitos com níveis de metaconglomerados e de grafite-cianita-andaluzita xistos) e Água Branca (quartzitos, filitos, xistos, formações ferríferas e metacherts com mineralizações de manganês; (iii) Complexo Itapicuru (Couto et al. 1978); e (iv) Sequência Metassedimentar do Greenstone Belt de Mundo Novo (Mascarenhas \& Silva 1994, Mascarenhas et al. 1998). A presença de filitos manganesíferos e de formações ferríferas bandadas nessas sequências metassedimentares pelíticas indica que seus protólitos foram depositados em ambiente de bacia marinha. Dados geocronológicos (métodos $\mathrm{U}-\mathrm{Pb}$ e $\mathrm{Pb}-\mathrm{Pb}$ ) em grãos detríticos de zircão definem duas populações distintas para o grupo Jacobina: $3,4-3,3$ Ga e 2,08 $\mathrm{Ga}$ (Mougeot, 1996). A primeira está relacionada às idades das fontes provenientes dos ortognaisses do Bloco Gavião, situados a oeste da bacia, enquanto a segunda indica fontes granulíticas e graníticas do Cinturão Salvador-Curaçá, situado a leste. Idades $\mathrm{Ar} / \mathrm{Ar}$ em micas entre 1,99 a 1,88 Ga balizam o período final de evolução térmica-metamórfica da bacia (Ledru et al. 1997).
O Complexo Saúde (Couto et al. 1978) é composto por uma associação de paragnaisses aluminosos que incluem kinzigitos e paragnaisses a cordierita, além de quartzitos, calcissilicáticas e anfibolitos. O metamorfismo nessas rochas é na fácies anfibolito, sendo que nos kinzigitos é anfibolito alto/granulito baixo, segundo idades que variam entre 2,08 e 2,05 Ga (Leite 2002).

Os leucogranitos são de filiação peraluminosa (Cuney et al. 1990, Leite 2002, Leite et al. 2007) e intrusivos ao longo dos contatos entre o Grupo Jacobina e o Complexo Saúde e os ortognaisses do Bloco Gavião, destacando-se o granito de Campo Formoso com idade de 1,88 Ga (Torquato et al. 1978, Sabaté et al. 1990b), considerado como pós-colisional ao evento paleoproterozoico regional (Sabaté et al. 1990b, Rudowski, 1989). Os leucogranitos sincolisionais apresentam estruturas de fluxo magmático e/ou foliação milonítica, controladas pela direção das tensões e pela intensidade da deformação regional (Leite et al. 2001). Suas idades de cristalização variam entre 2,15 e 2,08 Ga (Sabaté et al. 1990b, Leite 2002). A atividade intrusiva desse magmatismo no ambiente supracrustal representou importante gatilho termodinâmico que aumentou o grau geotérmico e mobilizou fluidos hidrotermais, resultando em importantes concentrações metalogenéticas no âmbito do Grupo Jacobina (Rudowski 1989, Leite 2002, Milési et al. 2002, Leite et al. 2005, Leite et al. 2007).

De acordo com Sabaté et al. (1990a, 1990b), Mascarenhas \& Silva (1994), Ledru et al. (1997), Mascarenhas et al. (1998), Leite (2002), Milési et al. (2002), Oliveira et al. (2004), duas importantes fases de deformação, ambas atribuídas à orogenia paleoproterozoica, riaciana-orisiriana, caracterizam a evolução estrutural dessas unidades geotectônicas. A primeira fase de deformação $\left(D_{1}\right)$ é atribuída a uma tectônica tangencial que formou falhas de empurrão com vergência para oeste e dobras isoclinais, recumbentes. A segunda $\left(\mathrm{D}_{2}\right)$ é caracterizada por dobras com planos axiais NNE-SSW, subverticalizados e por transcorrências dúcteis com alto ângulo de mergulho, paralelos aos domínios de dobramento (Ledru et al. 1997). Os contatos entre o embasamento, o Complexo Saúde e o Grupo Jacobina, bem como entre as formações constituintes desse grupo representam zonas de cisalhamento com forte mergulho, em geral para leste, que acompanham 
os domínios de transcorrência. Estruturas com indicadores cinemáticos, como lineações de estiramento mineral, superfícies $\mathrm{S}$ e C, dobras assimétricas indicam vergência das unidades geotectônicas para oeste com movimentação regional sinistral (Sabaté et al. 1990a, 1990b, Mascarenhas \& Silva 1994, Ledru et al. 1997, Mascarenhas et al. 1998, Leite 2002, Milési et al. 2002).

\section{Unidades litoestratigráficas e arcabouço es- trutural da Mina da Bananeira $\mathrm{Na}$ Mina} Bananeira afloram filitos, quartzitos com moscovita e formações ferro-manganesíferas, cujo posicionamento cronoestratigráfico é objeto de controvérsia (Greenstone Belt de Mundo Novo ou Grupo Jacobina) (Fig. 2). Os filitos apresentam cor castanha clara e são marcados pela sua foliação penetrativa. As formações ferro-manganesíferas alternam níveis ricos em manganês, níveis ricos em óxido de ferro, itabiríticos e metacherts. O contato entre níveis de composição diferenciada varia entre transicional e abrupto.

$\mathrm{Na}$ área em foco foram diferenciadas duas famílias de estruturas. A primeira, compressional,

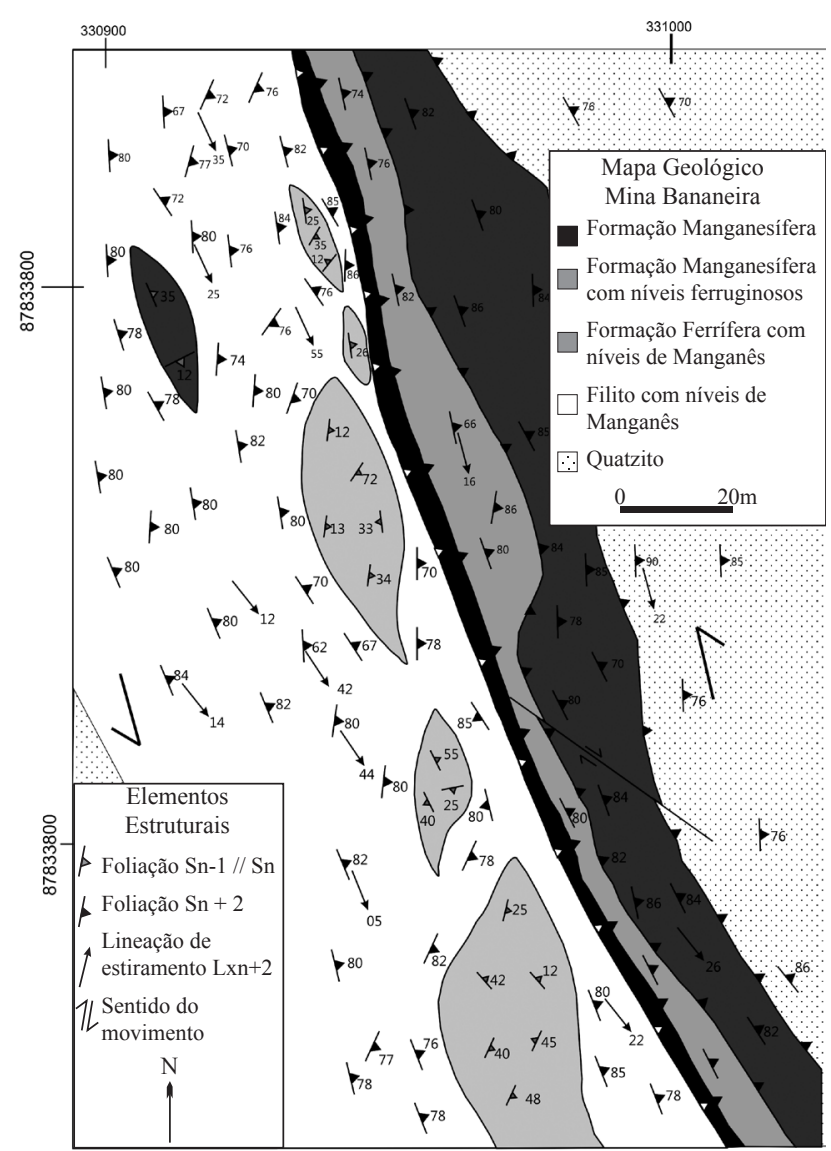

Figura 2 - Mapa geológico da Mina Bananeira, Miguel Calmon, Bahia. marca o registro de três estágios deformacionais dúcteis, Dn-1, Dn e Dn+1 e Dn+2. A segunda, distensional, compreende a fase $\mathrm{Dn}+3$, de caráter dúctil-rúptil. Um bandamento composicional Sn-1 é especialmente observado nas formações ferríferas e está associado com dobras intrafoliais internas à foliação da fase Dn. Nessa fase foi nucleada uma foliação Sn-1//Sn que é paralelizada ao bandamento composicional. Restos de dobras em bainha ocorrem distribuídos internamente à $\mathrm{Sn}$, principalmente, na porção oeste da mina (Fig. 3A). O eixo cônico dessas estruturas posiciona-se segundo 093/02 (Fig. 4A) e as dobras assimétricas associadas com essa estrutura sugerem vergência para W. As estruturas da fase $\mathrm{Dn}+1$ correspondem a uma grande variedade de componentes nucleados sob um campo compressional segundo ESE-WNW. Em geral as dobras dessa fase de deformação apresentam envoltórias assimétricas e vergentes para oeste. A foliação plano axial nessas estruturas é muito pouco desenvolvida, mas quando presente, sua posição confirma a vergência das assimetrias das envoltórias. Nessa família estão incluídas dobras com ampla variedade de estilos, podendo variar entre parasíticas simétricas e assimétricas. A maioria das dobras é cilíndrica, com charneira arredondada e, em geral, são desarmônicas. Dobras chevron podem ser observadas de forma subordinada. A posição do plano axial e da linha de charneira é bastante variada, tendo sido encontradas dobras que foram classificadas como normal horizontal, moderadamente inclinada horizontal e recumbente (Fig. 3B) (sensu Fleuty 1964). De acordo com o ângulo interflanco das dobras, o estilo varia entre aberto (ângulo inteflanco entre $60-120^{\circ}$ ), fechado (ângulo inteflanco entre $10-60^{\circ}$ ) e isoclinal (ângulo inteflanco entre $0-10^{\circ}$ ) (sensu Van Der Pluijm \& Marshak 2004). O levantamento realizado revelou uma ampla distribuição da Lbn+1 com bastante dispersão de orientação (Fig. 4B). Essa ampla dispersão de medidas possivelmente está relacionada com a interferência dessa fase com as estruturas rúpteis (Fase $\mathrm{Dn}+3$, descrita mais adiante).

A fase Dn+2 está representada por um conjunto de zonas de cisalhamento que ocorre ora contínua, ora anastomosada, e que transpõe parcialmente as estruturas anteriormente nucleadas (Figs. 3C e D). Essas zonas apresentam foliação milonítica com orientação preferencial segundo 084/77 (Figs. 3C e 5A). A lineação de 

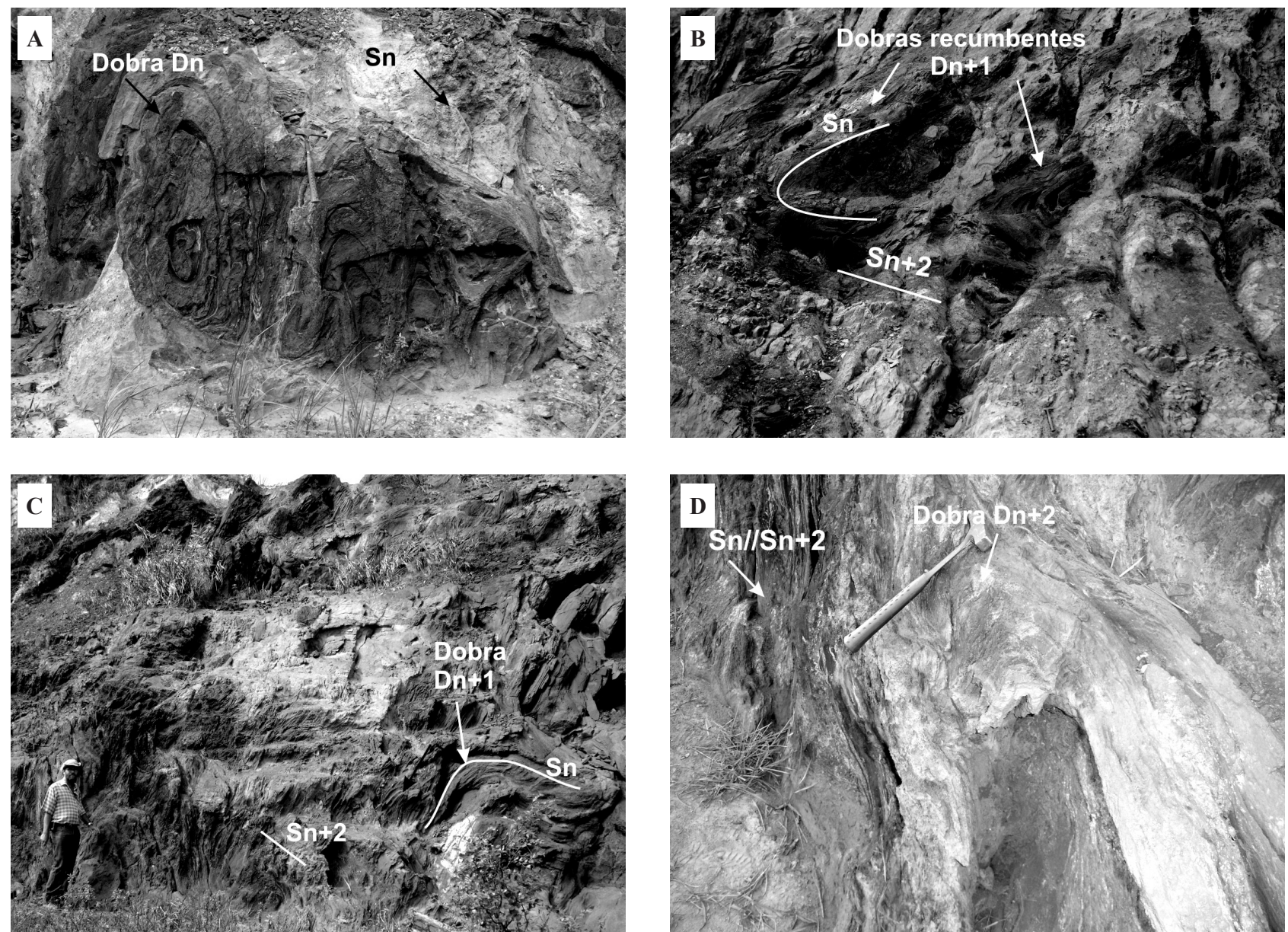

Figura 3 - Estruturas deformacionais encontradas na Mina Bananeira: (A) Dobras em bainha sin-Dn. Visada em seção; (B) Dobras recumbentes (sensu Fleuty, 1964) sin-Dn+1. Visada oblíqua, quase em seção; (C) Foliação Sn+2 truncando dobras da fase Dn+1. Visada em seção; (D) Dobras verticais (sensu Fleuty 1964) da fase Dn+2. Visada em planta.

A

Eixos de dobras em bainha -

Lbn Máximo = 093/02

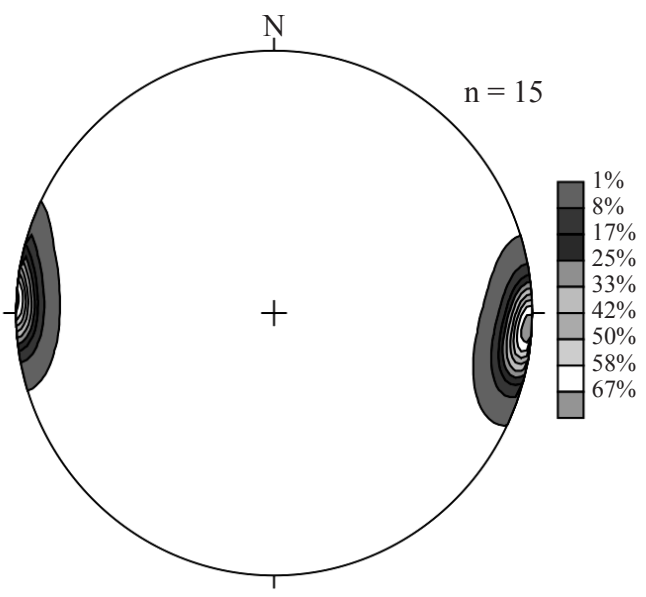

B

Eixos de Dobras - Lbn+1

Máximos $=262 / 02$ e 261/02

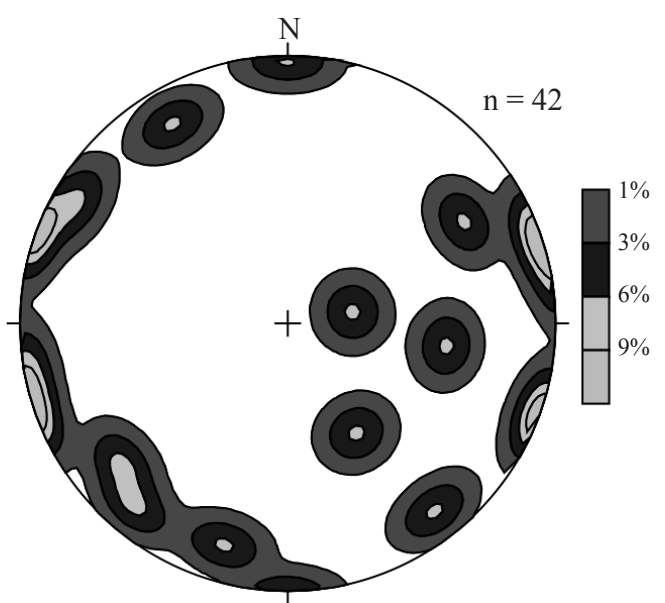

Figura 4 - Diagramas estereográficos sinópticos (Hemisfério inferior, rede equiárea) dos eixos de dobras das fases Dn (A) e Dn+1 (B). N: número de medidas.

estiramento $(\mathrm{Lxn}+2)$, desenvolvida sobre a foliação $\mathrm{Sn}+2$, orienta-se segundo 155/44 (Fig. 5b) e é marcada pelo quartzo. Estruturas do tipo $\mathrm{S} / \mathrm{C}$ sugerem movimentos sinistral-reversos para essas estruturas. No interior dessas zonas, dobras verticais (sensu Fleuty 1964) (Fig. 3D) 

Foliação metamórfica - $\mathrm{Sn}+2$
Máximo $=264 / 13$
A
Plano Mazimo: 084/77

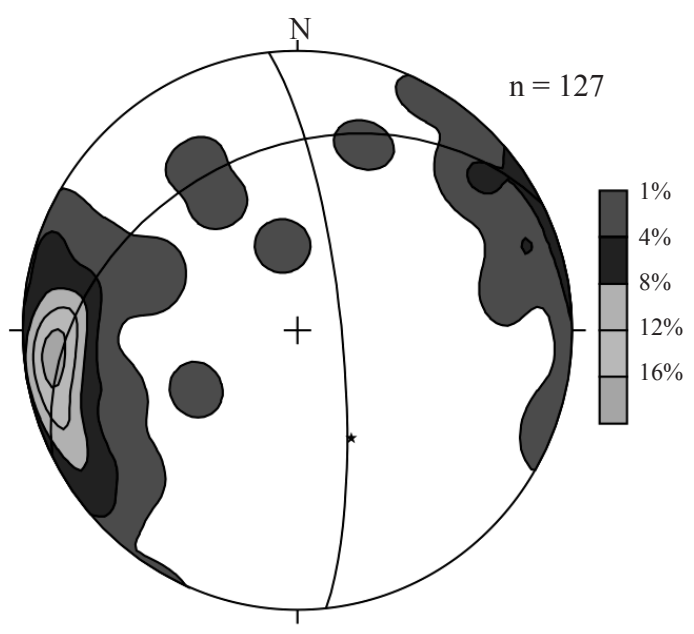

Eixos de dobras - $\mathrm{Lbn}+2$ Máximo $=162 / 76$

C

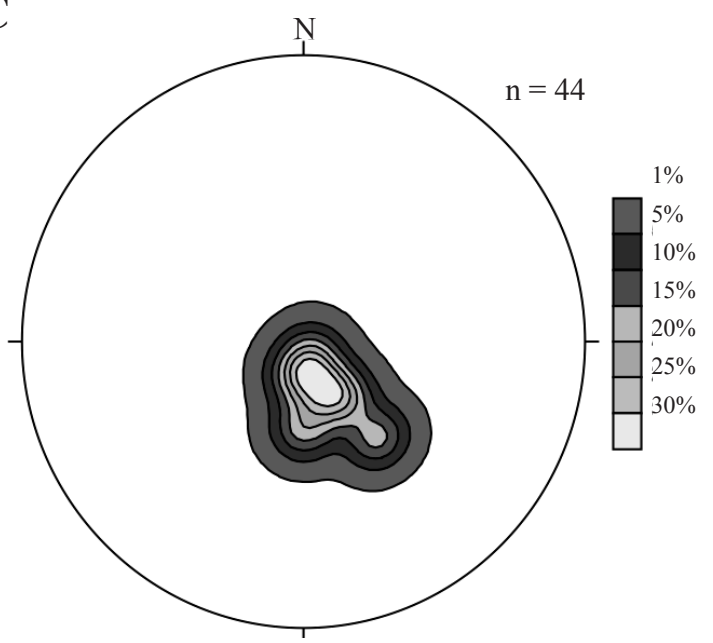

Lineação de estritamento mineral - $\mathrm{Lxn}+2$

B

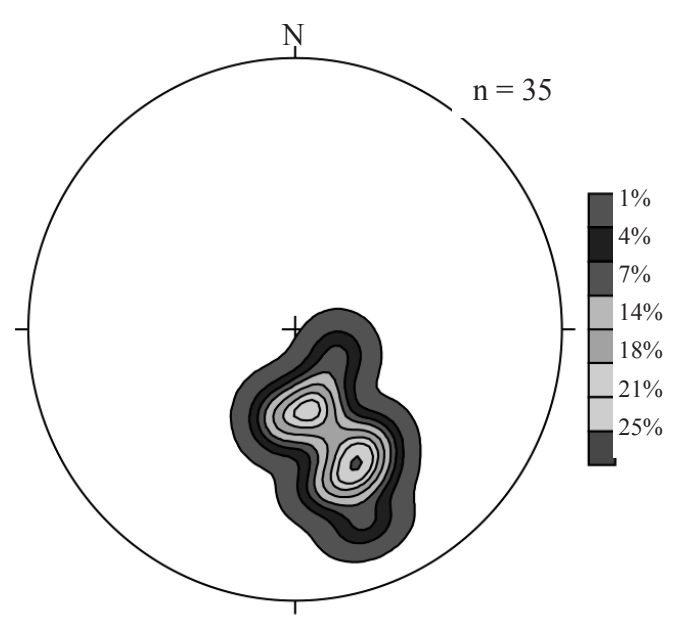

Estruturas Anti-Riedel (R') Dn+2

Máximo $=176 / 10$

Plano Máximo: 356/80

D

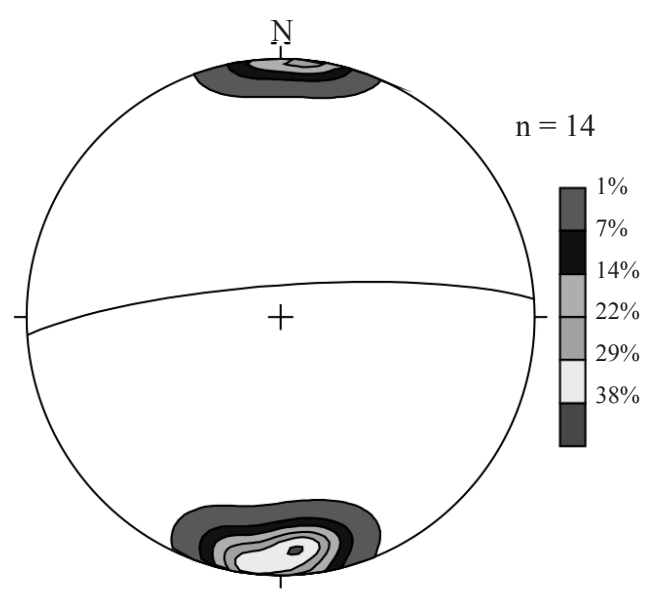

Figura 5 - Diagramas estereográficos sinópticos (Hemisfério inferior) das estruturas fase Dn+2. N: número de medidas.

e normal-moderadamente inclinadas (sensu Fleuty 1964) podem ser encontradas, cujas charneiras $(\mathrm{Lbn}+2)$ posicionam-se segundo 162/76 (Fig. 5C), em geral, subparalelamente à lineação de estiramento. Essas dobras podem representar domínios locais de deformação progressiva da foliação $\mathrm{Sn}+2$. Ainda associadas com a fase $\mathrm{Dn}+2$, estruturas do tipo R' podem ser encontradas. Tais estruturas são responsáveis pela nucleação de dominós antitéticos que possuem plano máximo segundo 356/80 (Fig. 5D). Em seu interior, o movimento geral é destral-reverso e a vergência é para ENE. Embora presentes estruturas das fases Dn e
$\mathrm{Dn}+1$, são as estruturas Dn+2 que dominam o arcabouço tectônico local (Fig. 6).

As rochas associadas com as zonas de cisalhamento $\mathrm{Dn}+2$ são filitos, hematita-quartzo-mica xisto e hematita xisto. Além disso, corpos de manganês maciço são encontrados paralelizados com a foliação principal e com as estruturas R'. É possível observar que em direção à porção central das zonas de cisalhamento, onde a deformação é mais intensa, há um enriquecimento em manganês e um empobrecimento em ferro. Nas bordas dessas zonas, ao contrário, cresce o conteúdo em termos mais ferrosos e diminui o conteúdo em manganês. 
Nos filitos é possível encontrar restos de níveis ferro-manganesíferos, de dimensões centimétricas a métricas, que se encontram contornados pelas zonas de cisalhamento $\mathrm{Dn}+1$. Essa variação química pode estar relacionada à mobilidade de elementos químicos por percolação de fluidos ao longo de zonas de cisalhamento (Leite 2002, Leite et al. 2007).

A partir da distribuição espacial das estruturas deformacionais das fases $\mathrm{Dn}+1$ e $\mathrm{Dn}+2$,

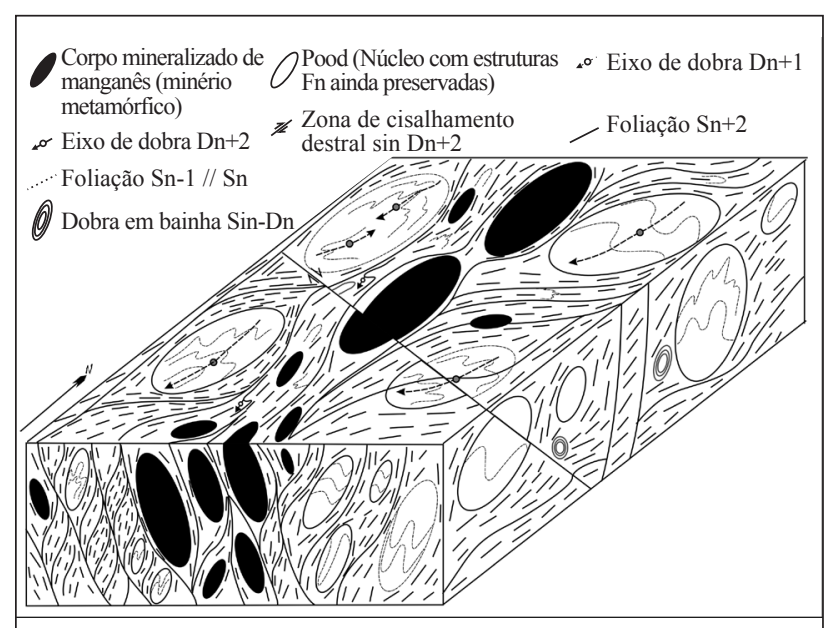

Figura 6-Arcabouço estrutural esquemático da Mina Bananeira. Nela só estão representadas as estruturas das fases $\mathrm{Dn}, \mathrm{Dn}+1$ e $\mathrm{Dn}+2$. foram definidos dois domínios estruturais distintos (Fig. 7). O domínio I é marcado pelas estruturas sigmoidais, nas quais estão preservadas as estruturas da fase $\mathrm{Dn}+1$. As formações ferro-manganesíferas apresentam-se bandadas e estruturadas segundo um trem de dobras com geometria diversa. No Domínio II, predominam as zonas de cisalhamento da fase $\mathrm{Dn}+2$.

As estruturas da fase $\mathrm{Dn}+2$ se encontram parcialmente reativadas e invertidas por um conjunto de zonas de cisalhamento normais, rúptil-dúcteis, da fase $\mathrm{Dn}+3$. No afloramento, tais zonas são preferencialmente instaladas nos filitos e no contato destes com os níveis de manganês maciço. Essas estruturas posicionam-se, preferencialmente, com atitude 080/77 (Fig. 8A). A disposição dessas zonas é muito semelhante àquelas da fase $\mathrm{Dn}+2$, entretanto a sua diferenciação é feita utilizando-se critérios cinemáticos. Os principais indicadores de movimento nessas zonas são as estruturas $\mathrm{S} / \mathrm{C}$ e dobras de arrasto que fornecem indicações de movimento normal, ao passo que as zonas de cisalhamento Dn+2 são compressionais. A foliação $\mathrm{Sn}+3$ é marcada por mica branca e quartzo e a lineação de estiramento mineral $\mathrm{Lxn}+3$, que pode ser encontrada segundo 120/55 (Fig. 8B), é

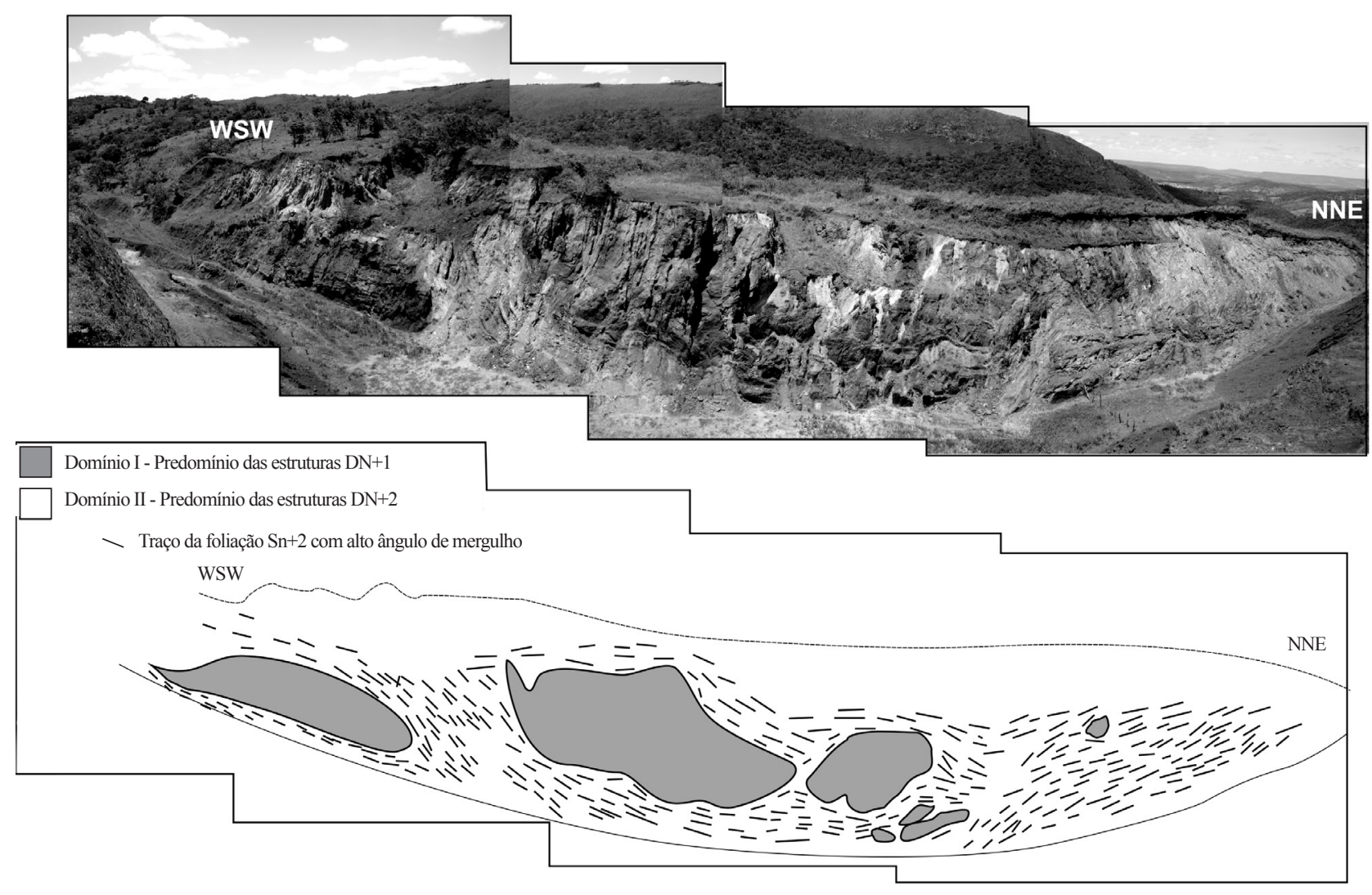

Figura 7 - Dominios estruturais identificados na Mina Bananeira. Visada inclinada da frente de lavra. 
A

$$
\begin{gathered}
\text { Foliação metamórfica }-\mathrm{Sn}+3 \\
\text { Máximo }=260 / 13 \\
\text { Plano Mazimo: 080/77 }
\end{gathered}
$$
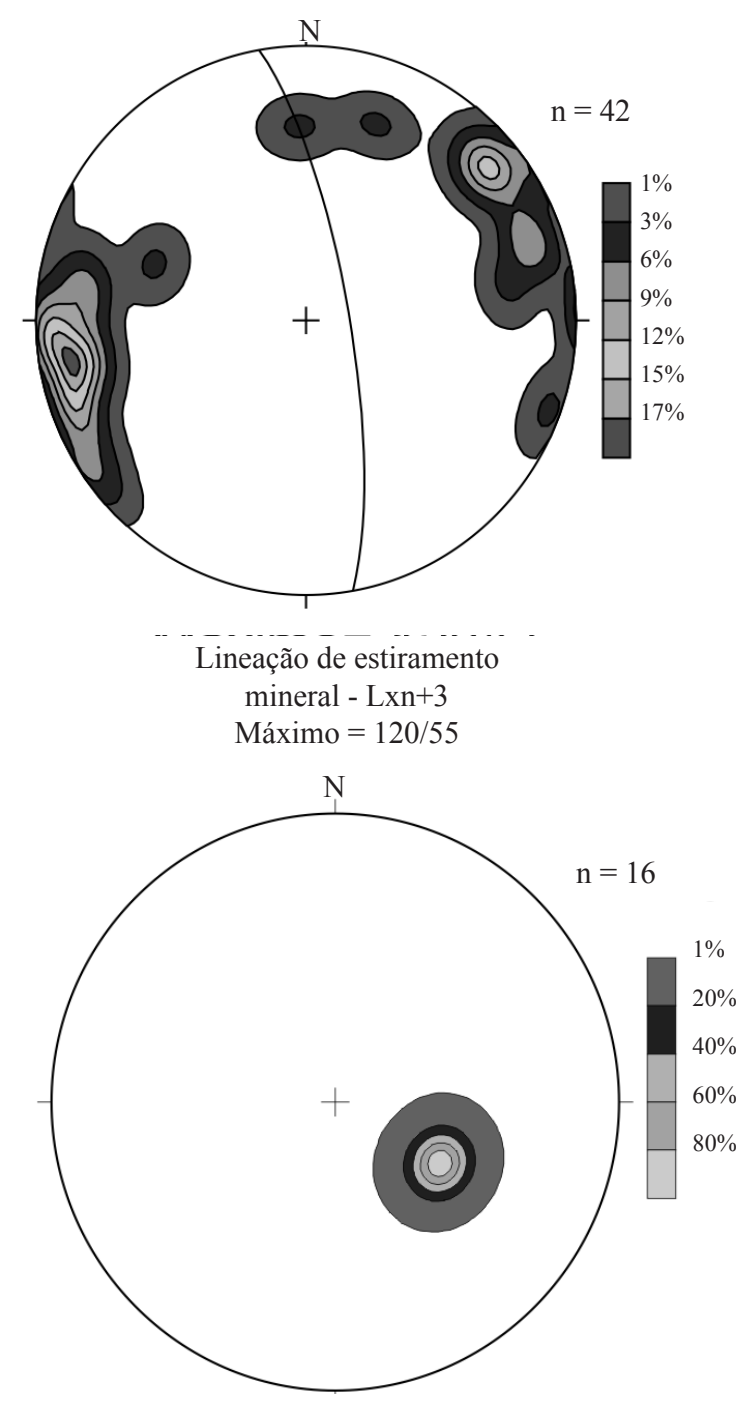

C

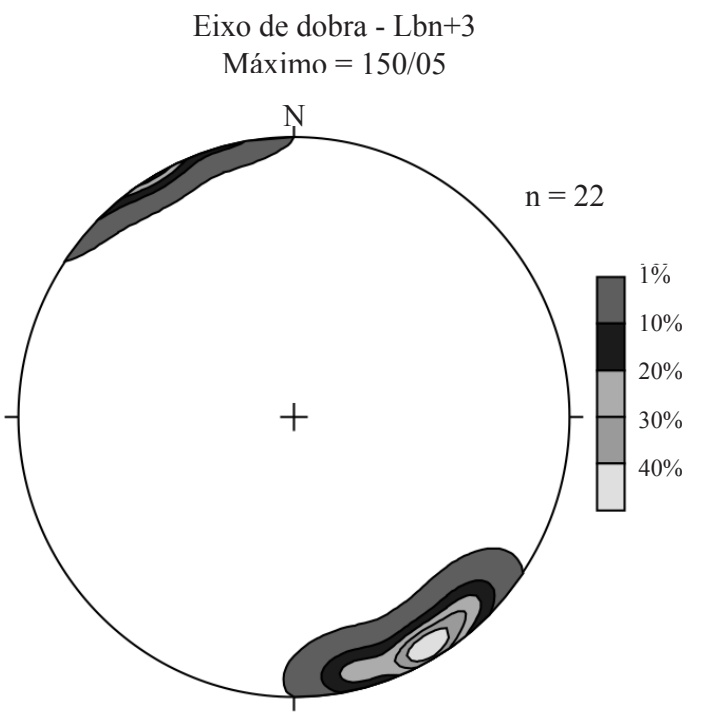

Figura 8 - Diagramas estereográficos sinópticos (Hemisfério inferior) das estruturas fase $D n+2 . N$ : número de medidas. assinala pelo quartzo. As dobras de arrasto desenvolvem-se sobre a foliação $\mathrm{Sn}$, podendo ser classificadas como recumbente, de acordo com a classificação de Fleuty (1964). A Lbn+3 posiciona-se preferencialmente segundo 150/05 (Fig. 8C).

Tardiamente à fase $\mathrm{Dn}+3$, são desenvolvidas zonas de cisalhamento rúpteis e fraturas de tração que truncam filitos, formações ferríferas e corpos maciços de manganês, indiscriminadamente (Figs. 9A - D). As fraturas de tração apresentam ampla variação de orientação (Figs. 10A e B), com predomínio de estruturas E-W. As zonas de cisalhamento rúpteis, com orientação geral 082/76 (Fig. 10c) foram responsáveis pela intensa fragmentação da rocha, por geração de cataclasitos e pelo desenvolvimento de estruturas do tipo stockwork. Além disso, nos domínios de maior deformação essas estruturas foram responsáveis pela rotação friccional das estruturas das fases anteriores, especialmente as dobras da fase Dn. Os fragmentos de rocha possuem granulometria variada, desde centimétrica até métrica, são angulosos e refletem a composição da rocha encaixante. No interior dessas fraturas, observa-se, com forte frequência, a presença da pirolusita sugerindo remobilizações supergênicas (Fig. 8D) a partir do minério metamórfico e que constitui o corpo maciço na mina que foi explotado por décadas (Fig. 6). Além disso, nos cataclasitos os fragmentos são cimentados pelos óxidos de manganês e ferro, que também podem ter migrado pela atuação de fluidos que percolaram as zonas de cisalhamento que truncam o minério metamórfico.

As brechas e cataclasitos da fase Dn+3 apresentam ampla variação de granulometria, forma e composição (Figs. 9A - D), com os fragmentos angulosos de tamanhos desde milimétricos a centimétricos e composição variada que pode contrastar com a da rocha encaixante. Nesse contexto, podem ser encontrados clastos de formação ferrífera-manganesífera, quartzitos e filitos que se encontram imersos em uma matriz rica em ferro. Não se observou a presença de imbricamentos dos clastos que pudessem sugerir a direção de transporte tectônico.

DISCUSSÃO Na Mina Bananeira podem ser identificadas estruturas das fases de estruturação e de colapso do Orógeno Salvador-Curaçá (Fig. 11). A fase deformacional mais antiga, Dn-1, está representada 

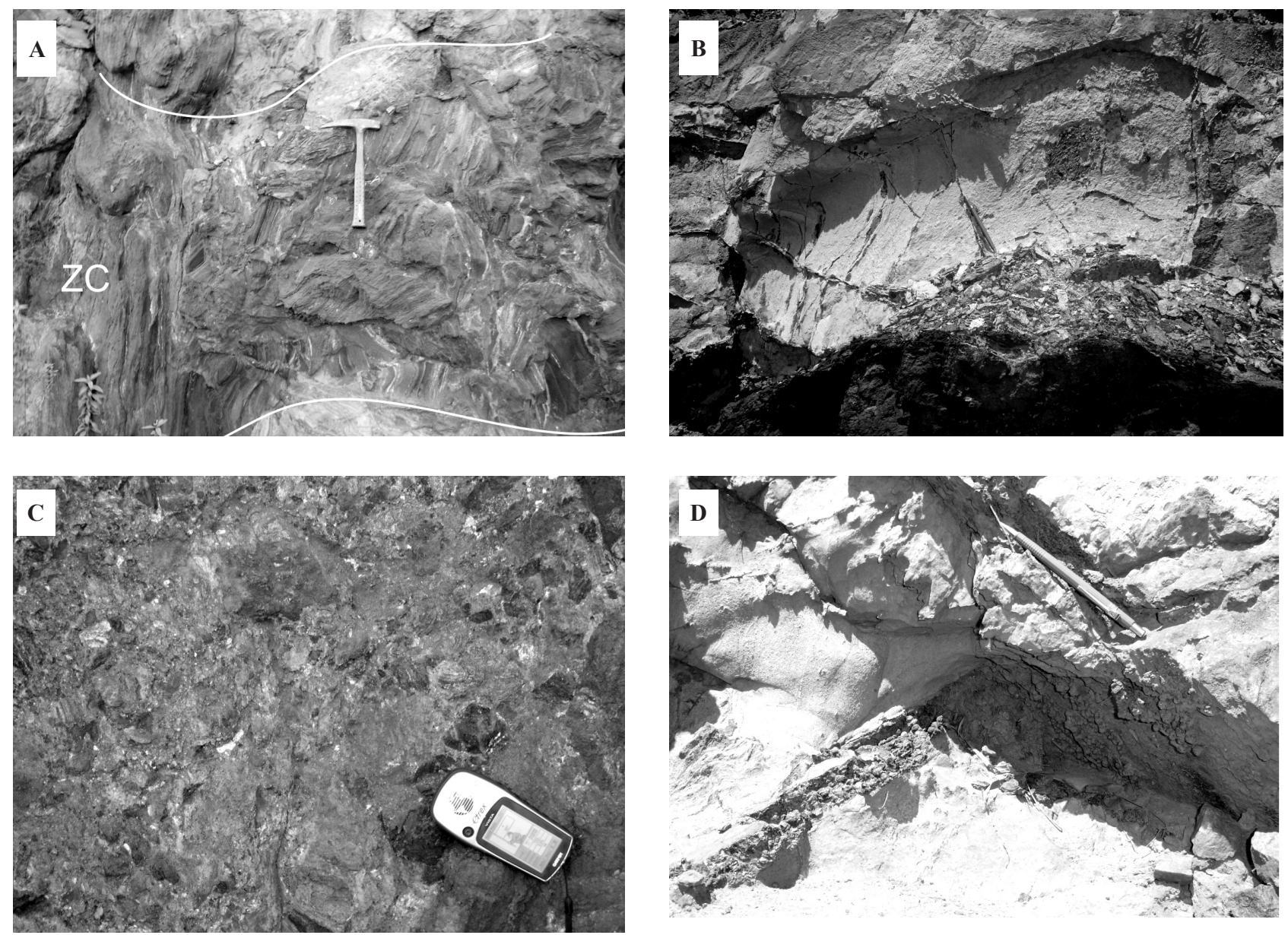

Figura 9 - Imagens das brechas e cataclasitos associados com zonas de cisalhamento rúpteis da fase Dn +3. O limite da zona de cisalhamento está marcado na fotografia:(A) brecha em formação ferrífera. Visada em planta; (B) brecha em formações ferriferas (camada escura) e fraturas com óxido de manganês em filitos (camada clara). Visada em planta; (C) cataclasito com fragmentos de formação ferrifera e filitos. Visada em seção; (D) fratura em filito com remobilização de manganês e crescimento da pirolusita. Visada em seção.

por um bandamento composicional que se encontra paralelizado a uma xistosidade, ambos observados em dobras isoclinais (Fig. 11A) internas à foliação da fase Dn. Durante essa fase, houve a formação de uma foliação $\mathrm{Sn}-1 / / \mathrm{Sn}$, bem como de lineação de estiramento mineral e dobras em bainha. O eixo dessas dobras sugere movimentos segundo, aproximadamente, E-W com vergência para W. A foliação Sn-1// Sn é rotacionada pela fase $\mathrm{Dn}+1$ levando ao desenvolvimento de dobras com estilos diversos. Ambas as fases são correlacionáveis com as deformações tangenciais de evolução do Cinturão Salvador-Curaçá propostas por Sabaté (1996, fase D1), cujos movimentos são frontais com topo estrutural para oeste.

$\mathrm{Na}$ fase seguinte, $\mathrm{Dn}+2$, zonas de cisalhamento sinistral-reversas com alto ângulo de mergulho foram nucleadas (Fig. 11B). Tais zonas, com orientação preferencial segundo NNW/ SSE, foram responsáveis pela transposição das estruturas anteriormente nucleadas. Na zona principal, os movimentos são oblíquos, reverso-sinistrais. Estruturas antitéticas, R', com movimento destral e orientação geral E-W foram também nucleadas durante essa fase deformacional. A distribuição das estruturas deformacionais e o campo cinemático sugerem que a deformação aconteceu em regime transpressional com tensor principal segundo NW-SE. A fase de deformação Dn+2 é correlacionável com a fase D2 de Sabaté (1996).

A fase deformacional $(\mathrm{Dn}+3)$ nucleou zonas de cisalhamento com movimento normal, rúptil-dúcteis (Fig. 11C). O alto ângulo dessas estruturas, associada com a orientação preferencial semelhante a das zonas de cisalhamento $\mathrm{Dn}+1$, sugere que processos de reativação e inversão tectônica estiveram presentes. A magnitude desses processos, entretanto, foi insuficiente para apagar os registros das deformações prévias. 


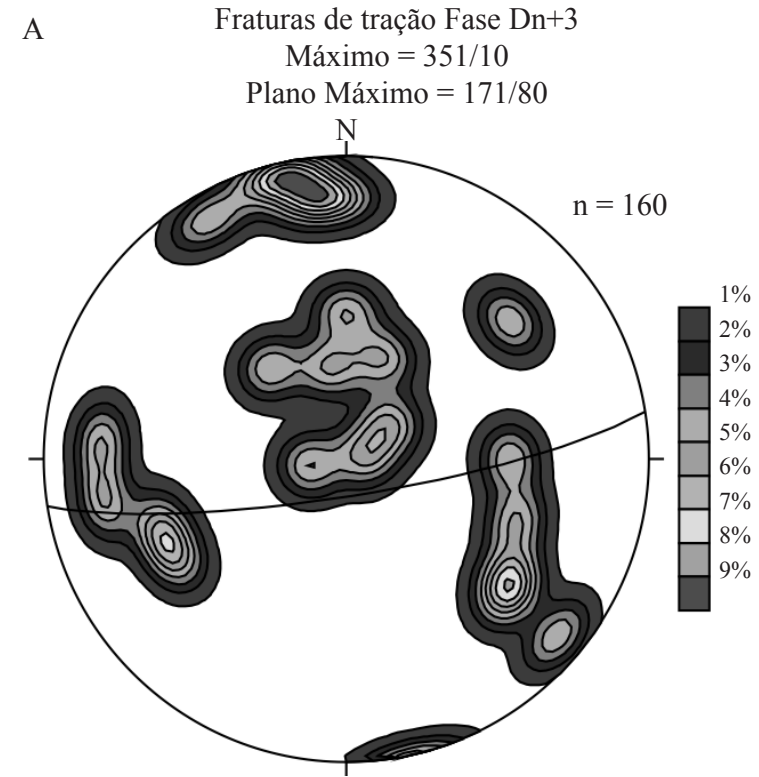

B

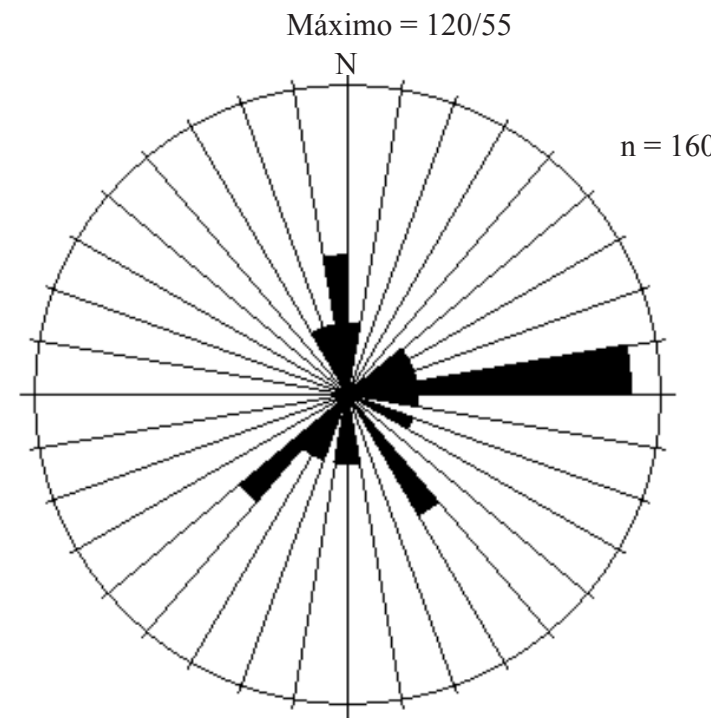

$\mathrm{C}$

Zonas de cisalhamento

Fase $\mathrm{Dn}+3$

Máximo $=262 / 14$

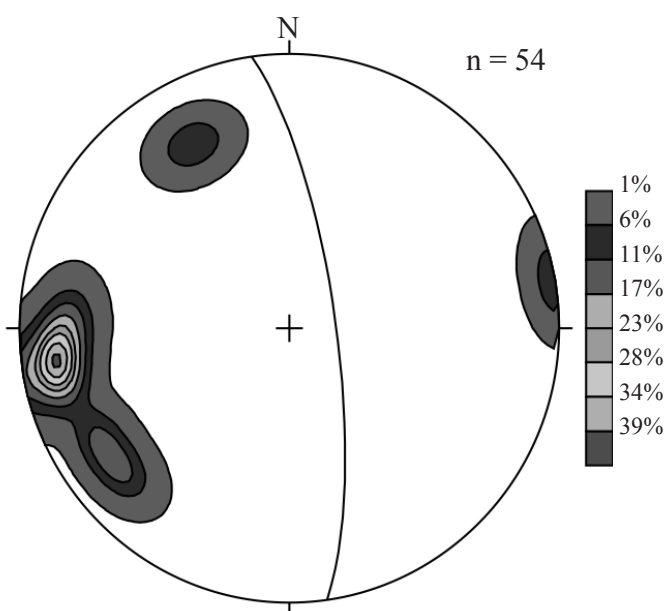

Figura 10 - Diagramas estereográficos sinópticos (Hemisfério inferior) ( $A$ e C) e de rosetas (B) das estruturas rúpteis da fase $D n+3$.
No final da fase Dn+3 houve a nucleação de fraturas e zonas de cisalhamento rúpteis com geração de brechas e cataclasitos (Fig. 11C). O intenso fraturamento gerou brechas tectônicas autóctones, ou seja, com arcabouço possuindo a mesma composição da encaixante, enriquecidas em manganês. Por outro lado, em algumas zonas de cisalhamento foram encontrados clastos com composição contrastante com a composição da rocha encaixante. Nesses casos, a matriz é rica em ferro e manganês, independente se a encaixante é rica ou pobre nesse elemento. Tais feições sugerem que se trata de material alóctone, que foi transportado por um fluido hidrotermal. Essas estruturas são os registros das fases finais do colapso orogenético, que teria gerado arqueamento positivo das rochas, abatimento da capa nas zonas de cisalhamento, fraturamento por sobrepressão de fluidos e abertura de espaços. A colocação dos granitos pós-tectônicos, apresentados por Sabaté (1996) pode ter propiciado a circulação de fluidos hidrotermais que lixiviaram o manganês de seus protólitos sedimentares reprecipitando-os ao longo das estruturas $\mathrm{Dn}+3$. Os fragmentos de rochas com composição distinta da encaixante sugerem a atuação de processos de denudação tectônica associados com fluidos hidrotermais.

CONCLUSÕES Na Mina Bananeira, podem ser identificadas estruturas das fases de estruturação transpressional do Orógeno SalvadorCuraçá (Fases Dn-1, Dn, Dn+1 e Dn+2), estruturas distensionais $\mathrm{Dn}+3$ que reativam as estruturas Dn+2 e geram um conjunto rúptil de brechas e cataclasitos. A Mina Bananeira guarda os registros das fases tangenciais de deformação do Orógeno Itabuna-Salvador-Curaçá, com assimetrias compatíveis com movimentos de leste para oeste. As estruturas mais antigas são dobras em bainha com geometria compatível com esse sentido de transporte tectônico. A envoltória das dobras assimétricas da fase $\mathrm{Dn}+1$ também revela essa vergência do movimento. A fase Dn+2 transpõe as estruturas anteriormente nucleadas, isolando núcleos pouco ou nada deformados, nos quais podem ser encontrados os registros das fases deformacionais anteriores. Elevadas pressões de fluidos nas fases finais de evolução (Fase $\mathrm{Dn}+3)$ propiciaram a geração de brechas tectônicas através de processo de fraturamento hidráulico, com remobilizações de manganês e transporte de fragmentos. 
a) Compressivo / Frontal - DN+1

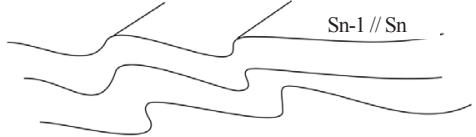

b) Transpressivo sinistral - Dn+2

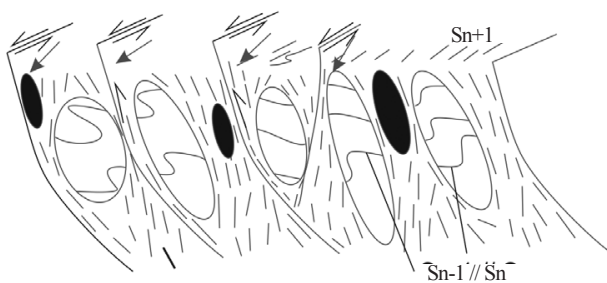

c) Distensional - $\mathrm{Dn}+3$
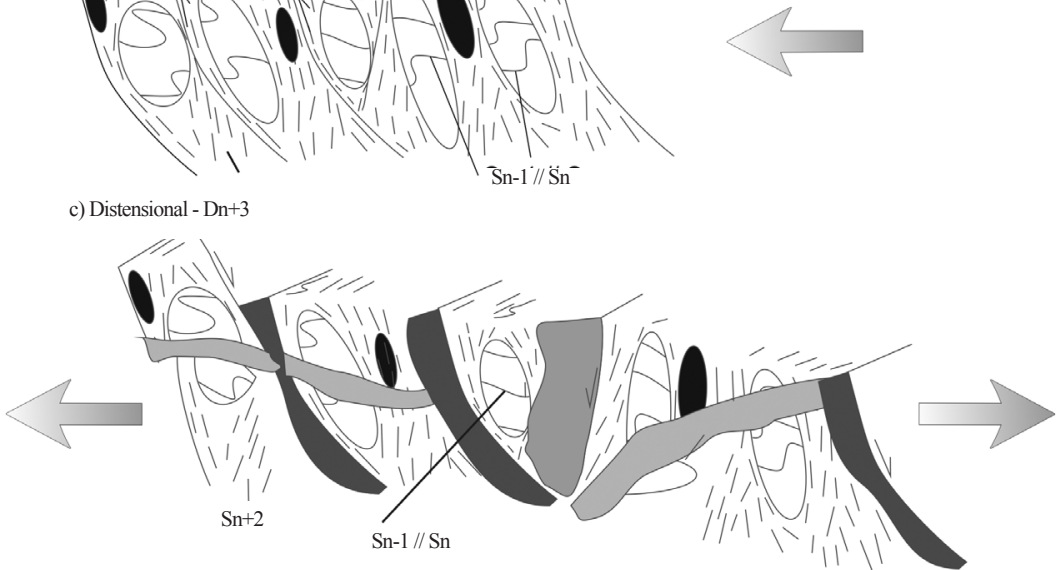

Legenda

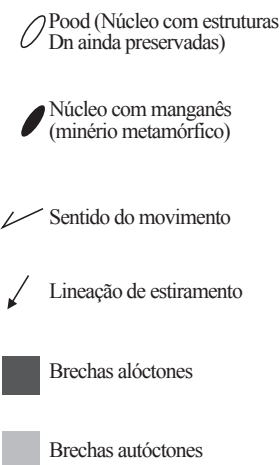
Dn ainda preservadas)

Brechas autóctones

Figura 11 - Modelo de evolução deformacional para a Mina Bananeira. Ver texto para discussão.

AGRADECIMENTOS Os autores querem expressar seus agradecimentos ao Conselho Nacional de Desenvolvimento Científico e Tecnológico (CNPq) pela bolsa Produtividade em Pesquisa (Processo 307590/2009-7) de Simone C. P. Cruz. Além disso, agradecem ao Thiago Xavier Novais pela digitalização do mapa.

\section{Referências}

Almeida F.F.M., de Hasui Y. 1984. Introdução. In: Almeida F.F.M. \& de Hasui Y. (eds.) O Pré-Cambriano do Brasil. São Paulo, Edgar Blücher, 378 p.

Barron C.N. 1966. Notes on the stratigraphy of Central British Guiana. In: DNPM, Conf. Geol. Interg., 6, Belém, Anais, p.121-126. Avulso n. 41.

Berrangé J.P. 1977. The geology of southern Guyana, South America. Overseas. Memoir 4, Institute of Geological Sciences, London, p.12.

Borges F.R. \& D’Antona R. de J.G. 1988. Geologia e mineralizações da serra Tepequém. In: SBG, Cong. Bras. Geol., 35, Belém, Anais, 1, p.155-163.

Bouman Q.C. 1959. The Roraima Formation, northern part of Territorio do Rio Branco. Rio de Janeiro, Petrobrás/Renor, Relatório Técnico 350-A, p.17.

Braun O.P.G. 1973. Projeto Roraima, 2 a Fase; Levantamento geológico integrado: Relatório de mapeamento preliminar ao milionésimo, correspondente à "Fotointerpretação preliminar". Manaus, DNPM/CPRM, 218 p. il.

Costa J.B.S., Pinheiro R.V.L., Reis N.J., Pessoa M.R., Pinheiro S. da S. 1991. O hemigraben do Tacutu, uma estrutura controlada pela geometria do Cinturão de Cisalhamento Guiana Central. Geociências, 10:119-130.

Fernandes Filho L.A. \& Nogueira A.C.R. 2003. Fácies de um Sistema Fluvial-Litorâneo Proterozoico na Serra do Tepequém, estado de Roraima. In: SBG, Simp. Geol. Amaz., 8, Manaus, CD-Rom.

Fernandes Filho L.A. 1990. Estratigrafia da Serra do Tepequém. In: SBG, Cong. Bras. Geol. 36, Natal, Anais, 1, p. 199-210.

Fernandes Filho L.A., Truckenbrodt W., Nogueira A.C.R. 2008. Fácies e estratigrafia da sucessão sedimentar Paleoproterozoica da Serra do Tepequém, sul do Escudo das Guianas. In: SBG, Cong. Bras. Geol., 44, Curitiba. Anais, CD-Rom.

Fraga L.M.B. 1999. Geologia Estrutural. In: Programa de Levantamento Geológicos Básicos do Brasil. Roraima Central, Folhas NA.20-X-B e NA.20-X-D (inteiras), NA.20$X-A, \quad N A .20-X-C, N A .21-V-A$ e NA.21-V-C (parciais). Escala 1:500.000. Estado do Amazonas, Brasília: CPRM, 1999. Relatório final, cap. 4, p. 117-128.

Fraga L.M.B. 2002. A Associação Anorrtosito-Mangerito Granito Rapakivi (AMG) do Cinturão Guiana Central e suas encaixantes paleoproterozoicas: Evolução estrutural, Geocronologia e Petrologia. Tese de Doutorado, Instituto de Geociências, Universidade Federal do Pará, 351 p.

Fraga L.M.B. 2010. Evolução tectônica. In: Fraga L.M.B., Dreher A.M., Grazziotin H., Reis N.J., Ragatky D. Geologia e Recursos Minerais da Folha Vila Tepequém 
- NA.20-X-A-III Estado de Roraima, escala 1:100.000. CPRM-SUREG-Manaus. (no prelo).

Fraga L.M.B., Grazziotin H., Dreher A.M., Farias M.S.G. 2010. Mapa Geológico. In: Fraga L.M.B., Dreher A.M., Grazziotin H., Reis N.J., Ragatky D. Geologia e Recursos Minerais da Folha Vila Tepequém - NA.20-X-A-III Estado de Roraima, escala 1:100.000. CPRM-SUREG-Manaus. (no prelo).

Fraga L.M.B., Macambira M.J.B., Dall'Agnol R., Costa J.B.S. 2009. 1,94-1,93 Ga charnockitic magmatism from the central parto f Guyana Sheild, Roraima, Brazil: Singlezircon evaporation data and tectonic implications. Journal of South American Earth Sciences, 27:247-257.

Fraga L.M.B., Reis N.J., Costa J.B.S. 1998. O Cinturão Guiana Central no Estado de Roraima. In: SBG, Cong. Bras. Geol., 40, Belo Horizonte, Anais, p. 411.

Fraga L.M.B., Reis N.J., Dall'Agnol R., Armstrong R. 2008. Cauarane-Coeroeni Belt - The tectonic southern limit of the preserved Rhyacian crustal domain in the Guyana Sheild, northern Amazonian craton. In: Int. Geol. Cong., 33, Oslo, Noruega. CD-Rom.

Fraga L.M.B., Reis N.J., Pinheiro S. da S. 1994a. Serra Tepequém: Uma estrutura relacionada à inversão da Bacia Roraima. In: SBG, Cong. Bras. Geol., 38, Camboriú, Resumo Expandido, p. 294-295.

Fraga L.M.B., Reis N.J., Pinheiro S. da S. 1994b. Arranjo estrutural do segmento sul do bloco Pacaraima, Estado de Roraima. In: SBG, Simp. Geol. Amaz., 4, Belém, Anais, p. 7-9.

Fraga L.M.B., Reis N.J., Riker S.R.L. 1999. Mapa Geológico. In: Programa de Levantamento Geológicos Básicos do Brasil. Roraima Central, Folhas NA.20-X-B e NA.20-X-D (inteiras), NA.20-X-A, NA.20-X-C, NA.21$V$-A e NA.21-V-C (parciais). Escala 1:500.000. Estado do Amazonas, Brasília, CPRM, 1999. Relatório final.

Gibbs A.K., Barron C.N. 1993. The Geology of the Guiana Shield. Oxford University Press, Oxford, 246 p.

Kroonenberg S.B. 1976. Amphibolite-facies and granulitefacies metamorphism in the Coeroeni-Lucie area, southwestern Surinam. Ph.D. Thesis, Amsterdan, Geologie em Mijnbouw, Dienst sur. Med., 25, p. 109289.

Lima M.I.C., Oliveira E.P., Tassinari C.C.G. 1982. Cinturões granulíticos da porção setentrional do Cáton Amazônico. In: SBG, Simp. Geol. Amaz., 1, Belém, Anais, 1, p. 147-162.

Montalvão R.M.G., Muniz M.B., Issler R.S., Dall'Agnol R., Lima M.I.C., Fernandes P.E.C.A., Silva G.G. 1975. Geologia da Folha NA.20 - Boa Vista e parte das Folhas NA.21 - Tumucumaque, NB.20 - Roraima e NB.21. In: Brasil. DNPM. Projeto RADAMBRASIL. Folha NA.20 - Boa Vista e parte das Folhas NA.21-Tumucumaque, NB.20 - Roraima e NB.21. Rio de Janeiro, 1975. (Levantamento de Recursos Minerais, 8).

Pinnheiro S.S., Reis N.J., Costi H.T. 1990. Geologia da Região de Caburaí - nordeste de Roraima. Relatório Final. Manaus, DNPM/CPRM, 1. il., 91 p.

Ramsay J.G. \& Huber M.I. 1983. The Techniques of Modern
Structural Geology: Strain Analysis. London, Oxford, Academic Press. 1. 307 p.

Ramsay J.G. \& Huber M.I. 1987. The Techniques of Modern Structural Geology: Folds and Fractures. London, Oxford, Academic Press. 2, 700 p.

Reid A.R. 1972. Stratigraphy of type area of the Roraima Group, Venezuela. In: Interg. Geol. Conf., 9, GeorgetownGuiana, p. 343-353, Boletim Especial 6.

Reis N.J. \& Carvalho A.S. 1996. Coberturas sedimentares do Mesoproterozoico do estado Roraima - Avaliação e discussão de seu modo de ocorrência. Revista Brasileira de Geociências, 26:217-226.

Reis N.J. \& Fraga L.M.B. 1999. Estratigrafia: Sinopse Estratigráfica. In: Fraga L.M.B. 1999. Programa de Levantamento Geológicos Básicos do Brasil. Roraima Central, Folhas NA.20-X-B e NA.20-X-D (inteiras), NA.20-X-A, NA.20-X-C, NA.21-V-A e NA.21-V-C (parciais). Escala 1:500.000. Estado do Amazonas, Brasília, CPRM, 1999. Relatório final, cap. 3.1, p. 15-17.

Reis N.J., Fraga L.M.B., Faria M.S.G. \& Almeida M.E. 2003. Geologia do Estado de Roraima, Brasil. In: Géologie de la France, vols. 2-4, p.121-134.

Santos J.O.S., Potter P.E., Reis N.J., Hartmann L.A., Fletcher I.R., McNaughton N.J. 2003. Age, source and Regional Stratigraphy of the Roraima Supergroup and Roraima-like Sequences in Northern South America, based on U-Pb Geochronology. Geological Society of America Bulletin, 115:331-348.

Santos J.O.S., Hartman L.A., Gaudette H.E., Groves D.J., Mcaugthon N.J., Fletcher R. 2000. A new understanding of the Provinces of the Amazon Craton based on ntergration of Field mapping and $\mathrm{U}-\mathrm{Pb}$ and $\mathrm{Sm}-\mathrm{Nd}$ geocronology. Gondwana Research, 3:453-488.

Schobbenhaus C., Hoppe A., Lork A. Baumann A. 1994. Idade $\mathrm{U} / \mathrm{Pb}$ do magmatiso Uatumã no norte do Cráton Amazônico, Escudo das Guianas (Brasil): Primeiros resultados. In: SBG, Cong. Bras. Geol., 38, Camboriú, Anais, 2, p. 395-397.

Tassinari C.C.G. \& Macambira M.J.B. 2004. A evolução tectônica do Cráton Amazônico. In: Mantesso Neto V., Bartorelli A. Carneiro C.D.R., Neves B.B.B. (orgs) Geologia do continente Sul-americano: evolução da obra de Fernando Flávio Marques de Almeida. São Paulo, BECA, p. 471-485.

Tassinari C.C.G., Bittencourt J.S., Geraldes M.C., Macambira M.J.B., Lafon J.M. 2000. The Amazonian Craton. In: Cordani U.G., Milani E.J., Thomaz Filho A., Campos D.A. (eds.) Tectonic Evolution of South America, Int. Geol. Cong., 31, Rio de Janeiro, Academia Brasileira de Ciências, p. 41-96.

Truckenbrodt W., Fernandes Filho L.A., Nogueira A.C.R., Reis N.J. 2008. Stratigraphy of Paleoproterozoic Arai Group, Southern part of Guyanas Sheild, Brazil. In: IAS-SEPM, Meeting of Sedimentology, 26, Bochum-Alemanha. CDRom.

Manuscrito ID 19399 Recebido em: 08/11/2010 Aprovado em: 12/08/2011 